\title{
INFLUÊNCIA DO MANEJO DO SOLO NAS PROPRIEDADES QUÍMICAS E FÍSICAS EM TOPOSSEQUÊNCIA NA BACIA DO RIO ARAGUAIA, ESTADO DO TOCANTINS ${ }^{(1)}$
}

\author{
Ana Flávia Gouveia de Faria ${ }^{(2)}$, Antonio Clementino dos Santos ${ }^{(3)}$, \\ Thiago Martins dos Santos ${ }^{(2)} \&$ Felipe Batistella Filho ${ }^{(4)}$
}

\begin{abstract}
RESUMO
A conversão do Cerrado nativo em áreas de exploração agrícola pode modificar os processos de decomposição e síntese da matéria orgânica do solo e, assim, na disponibilidade de nutrientes. Objetivou-se avaliar as propriedades químicas e físicas do solo em topossequência caracterizada por apresentar uso com pastagem cultivada com Brachiaria brizantha ao lado do Cerrado nativo, na camada de 0$15 \mathrm{~cm}$ de profundidade. O estudo foi realizado no município de Colmeia, Estado do Tocantins. Foram determinados 10 pontos de coleta (cinco para Cerrado nativo e cinco para pasto) para cada posição do relevo (topo, encosta e pedimento); em cada ponto amostral, foram coletados solos em três profundidades $(0-5,5-10$ e 10 $15 \mathrm{~cm}$ ), totalizando 90 amostras. Foram realizadas as seguintes análises químicas e físicas: C orgânico, $\mathrm{P}, \mathrm{K}^{+}, \mathrm{Ca}^{2+}, \mathrm{Mg}^{2+}, \mathrm{H}+\mathrm{Al}$, pH e granulometria. $\mathrm{O} \mathrm{C}$ orgânico não apresentou diferença $(p>0,05)$ entre os valores encontrados no Cerrado nativo e pastagem e as posições do relevo avaliadas. A conversão de Cerrado nativo para uso agropecuário reduziu os teores de $\mathrm{P}$. Os teores de $\mathrm{K}$ trocável não foram alterados pela retirada da cobertura vegetal original. Observou-se aumento dos teores de areia quando se passou da meia-encosta para o pedimento.
\end{abstract}

Termos de indexação: Cerrado nativo, pastagem, relevo.

\footnotetext{
(1) Recebido para publicação em março de 2008 e aprovado em fevereiro de 2010.

(2) Mestrando em Agronomia, Ciência do Solo, Faculdade de Ciências Agrárias e Veterinárias de Jaboticabal, Universidade Estadual Paulista - UNESP. Campus de Jaboticabal. Via de Acesso Prof. Paulo Donato Castellane s/n, CEP 14884-900 Jaboticabal (SP). E-mails: flaviazootec@hotmail.com; thiagozootecnia@hotmail.com

(3) Professor Adjunto III, Universidade Federal do Tocantins - UFTO. Br 153, km 112, Caixa Postal 132, CEP $77804-970$ Araguaína (TO). E-mail: clementino@uft.edu.br

(4) Doutorando em Agronomia, Ciência do Solo, Faculdade de Ciências Agrárias e Veterinárias de Jaboticabal, UNESP.
} 


\title{
SUMMARY: INFLUENCE OF SOIL MANAGEMENT ON CHEMICAL AND PHYSICAL SOIL PROPERTIES ALONG A TOPOSEQUENCE IN THE ARAGUAIA RIVER BASIN, STATE OF TOCANTINS
}

\begin{abstract}
The conversion of native vegetation into agricultural areas can modify soil organic matter content and decomposition and synthesis processes and therefore the nutrient avalilability. The aim of this study was to evaluate the chemical and physical soil properties $(0-15 \mathrm{~cm}$ depth) in a toposequence characterized by planted pasture beside the native Cerrado vegetation cover. The study was carried out in Colméia, State of Tocantins. Ten sampling points were determined (five samples in native vegetation and five samples in pasture) for each relief position (summit, midslope and footslope) and at each point soils were sampled at three depths (0-5, 5-10 and 10-15 cm), totaling 90 samples. The following chemical and physical properties were analyzed: organic $\mathrm{C}, \mathrm{P}, \mathrm{K}^{+}, \mathrm{Ca}^{2+}, \mathrm{Mg}^{2+}, \mathrm{H}+\mathrm{Al}, \mathrm{pH}$, and texture. Organic $C$ content found under native vegetation did not differ from pasture and the relief positions. The conversion from native vegetation to livestock use decreased P contents. The removal of native vegetation did not alter available K contents. There was an increase in sand content from midslope to the footslope positions.
\end{abstract}

Index terms: native vegetation, pasture, relief.

\section{INTRODUÇÃO}

Nas últimas décadas, as atividades agrícolas vêm modificando a cobertura vegetal original de parte do território brasileiro. Ecossistemas naturais, como o Cerrado e a floresta amazônica, vêm, há muito tempo, perdendo suas propriedades originais, devido à implantação de atividades agropecuárias ou extrativistas (Longo \& Spíndola, 2000). A expansão da fronteira agrícola, por desmatamentos, adoção de mecanização intensiva e uso de práticas de manejo inadequadas, promove alterações nas propriedades químicas, físicas e biológicas do solo, as quais levam ao processo de degradação, provocando redução da produtividade, principalmente devido à erosão superficial e consequente perda de nutrientes e matéria orgânica, o que torna a atividade agropastoril mais difícil e mais onerosa (Salton \& Hernani, 1998).

A degradação do solo pode ser entendida como redução da qualidade e produtividade do solo, devido principalmente a ações induzidas pelo homem. Em conseqüência disso, tem-se a perda de sustentabilidade, traduzida pela redução da capacidade do solo de produzir em determinado sistema de manejo (Dechen et al., 2004). Por ser o solo recurso de fundamental importância para a produção de alimentos e matériaprima, a conservação e recuperação para manutenção de sua qualidade são primordiais à preservação (Moreti et al., 2007).

Mesmo em solos de baixa fertilidade, florestas exuberantes não apresentam sintomas de deficiência nutricional, uma vez que o ciclo de nutrientes é praticamente fechado, verificando-se, ao longo do ano, contínua decomposição do material orgânico, associada à pequena perda por lixiviação e absorção de elementos (Silva et al., 2007). Com isso, observa-se que, nos solos sob Cerrado nativo, as perdas de nutrientes do ecossistema são menores em relação àqueles sob pastagem, devido principalmente à melhor cobertura do solo durante todo o ano e à menor decomposição do material vegetal (Fonseca, 1984).

A formação da camada de serrapilheira reflete equilíbrio entre produção e decomposição no sistema. A serrapilheira contribui, juntamente com os diversos compartimentos florestais, para a interceptação das águas da chuva, por meio do amortecimento e consequente dispersão da energia cinética das gotas, minimizando assim os efeitos erosivos. Por meio de gradiente vertical de decomposição, a camada de serrapilheira é responsável pelo armazenamento de água no solo, bem como pelo aumento das taxas de infiltração e condicionamento dos fluxos superficiais (Oliveira, 1987).

A conversão de ecossistemas naturais em áreas de exploração agrícola pode trazer sensíveis modificações nos processos de decomposição e síntese da matéria orgânica, C e N, decorrentes de alterações no fornecimento de material para incorporação ao solo (Longo \& Spíndola, 2000; Fraga \& Salcedo, 2004). O método mais comumente usado nessa conversão é o corte seguido de queima, o qual ocasiona quebra dos ciclos biogeoquímicos, com liberação de nutrientes imobilizados na biomassa florestal e emissão de partículas e gases para a atmosfera (Bonilla, 2005).

O efeito imediato depois da queima é o desaparecimento da serrapilheira e aumento do $\mathrm{pH}$ devido às cinzas. Como resultado, ocorre incremento transitório das condições de fertilidade do solo, já que o pH mais elevado favorece a taxa de troca de cátions e aumenta os teores de $\mathrm{P}, \mathrm{K}^{+}$e $\mathrm{Mg}^{2+}$. No entanto, esses teores não são suficientes para a nutrição das plantas e, geralmente no decorrer dos anos, voltam às concentrações similares da floresta de origem (Martins et al., 1991; Moraes et al., 1996; Diez et al., 1997; Bonilla, 2005). 
A variação de altitude e a diversidade de formas de relevo influenciam na drenagem e na presença de espécies vegetais, assim como nas possibilidades de uso das terras. A retirada da cobertura vegetal original expõe o solo a processos erosivos. A erosão pode ser mais marcante na encosta e aumenta de intensidade com o incremento da declividade. O estudo do solo em topossequência permite uma visão global e integrada dos vários componentes da paisagem. As topossequências têm sido utilizadas para compreender a pedogênese e o comportamento atual dos solos, sobretudo por estabelecer relações entre atributos do solo e relevo. Permitem elucidar as dinâmicas interna e externa do solo, a partir das suas variações verticais e laterais nas vertentes da bacia hidrográfica (Alves \& Ribeiro, 1995).

Quando a topossequência de vegetação nativa é convertida para a cultivada, pode haver perda de nutrientes ao longo do declive, em decorrência de práticas agrícolas inadequadas. Com a continuação do cultivo, as áreas convexas (nas encostas) apresentam perdas progressivas de sedimentos, enquanto as áreas côncavas atuam como áreas de deposição (Santos, 2004). As alterações nas características químicas dos solos pelo uso agrícola, comparativamente ao solo original desenvolvido sob floresta em topossequência, têm sido bastante discutidas, apesar dos poucos resultados de pesquisas regionais. Há, portanto, a necessidade de estudos que analisem a substituição de floresta por pastagem, verificando os impactos dessa atividade no solo (Silva et al., 2007). Com base no exposto, objetivou-se avaliar as propriedades químicas e físicas do solo em topossequência caracterizada por apresentar uso com pastagem cultivada com Brachiaria brizantha ao lado do Cerrado nativo, na camada de $0-15 \mathrm{~cm}$ de profundidade.

\section{MATERIAL E MÉTODOS}

O estudo foi realizado no município de Colmeia, Estado do Tocantins. O solo da área é classificado como Latossolo Vermelho-Amarelo (Embrapa, 1999). A temperatura média anual é de $28^{\circ} \mathrm{C}$, com precipitação pluvial de $1.800 \mathrm{~mm}$. O clima é considerado por Köpen como tropical úmido com duas estações bem definidas: uma chuvosa, de outubro a abril, e outra seca, de maio a setembro.

As amostras de solo foram coletadas em área que se caracteriza por apresentar o uso agrícola com pastagem de Brachiaria brizantha cultivada por um período de 15 anos ao lado de Cerrado nativo, ao longo de uma topossequência. Foram determinados 15 pontos de coleta para cada tipo de manejo de solo (15 pontos para pastagem e 15 para Cerrado nativo); desses pontos, cinco eram para topo, cinco para meiaencosta e cinco para pedimento dentro de cada tipo de manejo. As amostras de solo foram coletadas com auxílio de trado holandês em uma malha regular de $30 \times 30 \mathrm{~m}$, em três profundidades $(0-5,5-10$ e 10 $15 \mathrm{~cm}$ ), totalizando 90 amostras.

As amostras de solo foram secas ao ar, destorroadas e passadas na peneira com malha de $2 \mathrm{~mm}$ de diâmetro, para obtenção da terra fina seca ao ar (TFSA). As análises químicas realizadas foram: C orgânico, determinado após oxidação com dicromato de potássio na presença de ácido sulfúrico e titulação do excesso de dicromato com sulfato ferroso amoniacal (Camargo et al., 1986); o pH foi medido em suspensão solo- $\mathrm{CaCl}_{2}$ $0,01 \mathrm{~mol} \mathrm{~L}^{-1}$, na relação 1:2,5; e a acidez total do solo foi determinada extraindo o $\mathrm{H}+\mathrm{Al}$ com solução de acetato de cálcio tamponada a pH 7,1. Cálcio e Mg trocáveis foram extraídos por $\mathrm{KCl} 1 \mathrm{~mol} \mathrm{~L}^{-1}$ e determinados pelo método complexométrico com o emprego de EDTA 0,0125 $\mathrm{mol} \mathrm{L}^{-1}$, conforme Embrapa (1997). As demais análises químicas do solo foram: $\mathrm{Na}$ e K trocáveis e P assimilável, extraídos por Mehlich-1 (HCl $0,05 \mathrm{~mol} \mathrm{~L}^{-1}+\mathrm{H}_{2} \mathrm{SO}_{4} 0,0125 \mathrm{~mol} \mathrm{~L}^{-1}$ ), sendo o $\mathrm{K}$ e o Na determinados por fotometria de chama e o P por colorimetria (Embrapa, 1997). Os atributos físicos do solo analisados foram a granulometria, determinada a partir do método do densímetro de Bouyoucos descrito por Day (1965).

A análise da dependência espacial foi feita por meio de ajuste dos dados ao semivariograma experimental. Realizou-se a seleção dos modelos com base no melhor coeficiente de determinação $\left(R^{2}\right)$. Após obtenção dos gráficos de ajuste do modelo do semivariograma, foi feita a interpolação de dados por krigagem, de modo a definir o padrão espacial das variáveis estudadas, utilizando-se o programa GS ${ }^{+}$(Robertson, 1998). Os atributos que não variaram de forma espacial foram analisados pelo teste de Tukey a $5 \%$.

\section{RESULTADOS E DISCUSSÃO}

Os teores de C orgânico não apresentaram diferença $(p>0,05)$ para o Cerrado nativo e pastagem, bem como nas posições do relevo (Quadro 1). Esse comportamento pode estar relacionado com a incorporação ao solo de $\mathrm{C}$ proveniente da decomposição do sistema radicular da pastagem.

Esses resultados concordam com os obtidos por Greeland \& Nye (1959), os quais afirmam que, na maioria das regiões florestadas, os teores de $\mathrm{C}$ orgânico não alteram significativamente depois da retirada da floresta, não provocando distúrbio ao solo. Em relação ao estabelecimento de pastagem, Choné et al. (1991) e Cerri et al. (1992) demonstraram que esta pode não só recuperar os teores de C, como, em alguns casos, superá-los. No entanto, vários autores (Sanchez et al., 1983; Martins et al., 1990; Cerri et al., 1991; Moraes, 1991; Veldkamp, 1994) observaram que a substituição da vegetação nativa por sistemas cultivados provoca diminuição nos teores de $\mathrm{C}$ do solo. 
Quadro 1. Carbono orgânico e P disponível de 0-15 cm em diferentes manejos e posições do relevo em uma topossequência

\begin{tabular}{|c|c|c|c|c|c|c|}
\hline & \multicolumn{3}{|c|}{ Pastagem } & \multicolumn{3}{|c|}{ Cerrado nativo } \\
\hline & Média & Máximo & Mínimo & Média & Máximo & Mínimo \\
\hline & \multicolumn{6}{|c|}{ Topo } \\
\hline $\mathrm{C}$ orgânico $\left(\mathrm{g} \mathrm{kg}^{-1}\right)$ & $32,13 \mathrm{Aa} \pm 10,25$ & 52,2 & 18,20 & $26,2 \mathrm{Aa} \pm 8,56$ & 38,40 & 12,60 \\
\hline $\mathrm{P}$ disponível $\left(\mathrm{mg} \mathrm{dm}^{-3}\right)$ & $0,83 \mathrm{Aa} \pm 0,06$ & 0,96 & 0,74 & $0,86 \mathrm{Ab} \pm 0,18$ & 1,22 & 0,66 \\
\hline C orgânico $\left(\mathrm{g} \mathrm{kg}^{-1}\right)$ & \multicolumn{6}{|c|}{ Meia-encosta } \\
\hline $\mathrm{P}$ disponível $\left(\mathrm{mg} \mathrm{dm}^{-3}\right)$ & $0,92 \mathrm{Ba} \pm 0,17$ & 1,23 & 0,68 & $1,11 \mathrm{Aa} \pm 0,08$ & 1,22 & 0,95 \\
\hline $\mathrm{C}$ orgânico $\left(\mathrm{g} \mathrm{kg}^{-1}\right)$ & \multicolumn{6}{|c|}{ Pedimento } \\
\hline $\mathrm{P}$ disponível $\left(\mathrm{mg} \mathrm{dm}^{-3}\right)$ & $0,82 \mathrm{Ba} \pm 0,16$ & 1,12 & 0,60 & $1,06 \mathrm{Aa} \pm 0,21$ & 1,39 & 0,77 \\
\hline
\end{tabular}

Letras diferentes indicam diferença significativa a $1 \%$ pelo teste de Tukey Letras minúsculas indicam comparação de posição do relevo. Letras maiúsculas indicam comparação de uso do solo. \pm : desvio-padrão.

Segundo Fernandes (2002), na camada de 0-10 cm não houve diferença significativa no teor de $\mathrm{C}$ no solo sob pastagem estabelecida há 10 anos $\left(9,4 \mathrm{mg} \mathrm{dm}^{-3}\right.$ de $\mathrm{C}$ ), em relação ao solo sob Cerrado nativo $\left(9,0 \mathrm{mg} \mathrm{dm}^{-3} \mathrm{de} \mathrm{C}\right)$. No solo sob pastagem de 20 anos, o estoque de $\mathrm{C}\left(5,0 \mathrm{mg} \mathrm{dm}^{-3}\right)$ foi inferior ao observado no solo sob Cerrado nativo $\left(6,7 \mathrm{mg} \mathrm{dm}^{-3}\right)$ de C. O processo de desmatamento e queima para conversão de áreas nativas em agricultura resulta em redução acentuada no conteúdo de $\mathrm{C}$ do solo. Entretanto, com o passar do tempo, quando o solo é submetido a manejos conservacionistas, Salton (2005) firma que o conteúdo de $\mathrm{C}$ pode igualar ou até superar os sob floresta. Lal (2002) relaciona esse acúmulo de C à eficiência de ciclagem de nutrientes do sistema radicular das gramíneas. Roscoe et al. (2001) atribuíram esses resultados à elevada produção de resíduos pela pastagem.

Os valores observados de $\mathrm{P}$ disponível no Cerrado nativo apresentaram-se superiores $(p<0,01)$ em comparação ao uso agropecuário (Quadro 1). Quanto às posições do relevo, constatou-se superioridade $(p<0,01)$ no pedimento e meia-encosta em relação ao topo. Um dos motivos pode ser a ausência da ação antrópica no Cerrado nativo, que mantém o teor de $\mathrm{P}$ estável. O P é elemento pouco móvel, permanecendo no local onde foi depositado (Falleiro et al., 2003). Outro motivo para menores valores de $\mathrm{P}$ disponível no solo sob pastagem pode estar relacionado à ausência da adubação fosfatada. De acordo com Addiscott \& Thomas (2000), a ausência de revolvimento e a manutenção de resíduos culturais na superfície (serrapilheira) contribuem para aumento dos teores desse nutriente no solo.

Não houve diferença $(p>0,05)$ de teores de $C$ orgânico nas profundidades de $0-5$ e $5-10 \mathrm{~cm}$ (Figura 1a), na pastagem e no Cerrado nativo. Entretanto, na profundidade de $10-15 \mathrm{~cm}$, os valores encontrados na área de pastagem mostraram-se superiores em comparação aos do Cerrado nativo $(\mathrm{p}<0,01)$, devido, provavelmente, ao ciclo relativamente curto das gramíneas (75 a 90 dias), promovendo maior adição de material orgânico ao solo oriundo das raízes. Estes resultados concordam com os de Demattê (1996), que verificou que a redução do teor de matéria orgânica do solo com Cerrado nativo, quando comparado ao cultivado, deve-se ao aumento da taxa de decomposição da matéria orgânica estabilizada, devido ao desequilíbrio causado pelo cultivo. Os teores de P disponível (Figura 1b) no Cerrado nativo foram superiores aos da pastagem



Figura 1. Teores de C orgânico (a) e P disponível (b), em função da profundidade e de sistemas de manejo do solo. Letras diferentes indicam diferença significativa do sistema de manejo do solo a $1 \%$ pelo teste de Tukey. 
cultivada $(\mathrm{p}<0,05)$, nas três profundidades avaliadas. $\mathrm{Na}$ pastagem, há exportação de nutrientes, principalmente pela alimentação animal, o que não ocorre no Cerrado, onde há formação de serrapilheira.

Nas pastagens, o P disponível na camada superficial do solo normalmente cai drasticamente com o tempo após o estabelecimento desta, dada a interrupção brusca do processo de ciclagem de nutrientes pela derrubada da vegetação natural.

O acúmulo de $\mathrm{P}$ na superfície do solo é decorrente da decomposição dos resíduos de plantas e da diminuição da fixação em função do seu menor contato com os constituintes inorgânicos do solo (Moraes, 1993). Ecossistemas como o Cerrado nativo, que atingiram o equilíbrio entre a absorção e o retorno de nutrientes ao solo, têm grande parte das necessidades nutricionais das plantas suprida pelo processo de ciclagem. O desmatamento para implantação da pastagem altera o estado de equilíbrio de ecossistemas florestais por meio do aumento da velocidade de decomposição ou da destruição da serrapilheira. Essas práticas de manejo devem ser evitadas (Fonseca, 1984), e o $\mathrm{P}$ exportado pelas pastagens por intermédio da alimentação animal deve ser reposto via adubação. Em geral, independentemente do manejo do solo, predominaram teores baixos de P, devido provavelmente à fixação de $\mathrm{P}$ por óxidos e hidróxidos de $\mathrm{Fe}$ e $\mathrm{Al}$ nos solos com altos teores de argila (Figura 2).



LONGITUDE, UTM

Figura 2. Distribuição espacial do $\mathrm{Ca}^{2+}\left(\mathrm{cmol}_{\mathrm{c}} \mathrm{dm}^{-3}\right), \mathrm{Mg}^{2+}\left(\mathrm{cmol}_{\mathrm{c}} \mathrm{dm}^{-3}\right), \mathrm{K}^{+}\left(\mathrm{cmol}_{\mathrm{c}} \mathrm{dm}^{-3}\right), \mathrm{pH}, \mathrm{H}+\mathrm{Al}$ $\left(\mathrm{cmol}_{\mathrm{c}} \mathrm{dm}^{-3}\right)$, areia (\%), silte (\%) e argila (\%) em função de sistemas de manejo do solo e posições do relevo. a, b e c correspondem a 0-5, 5-10 e 10-15 cm de profundidade, respectivamente. Compartimentos I e II representam pastagem cultivada com Brachiaria brizantha e Cerrado nativo, respectivamente. Latitudes entre 740913 e 740810 representam o pedimento; entre 740810 e 740708 , a encosta; e entre 740708 e 740605, o topo da topossequência estudada. 
Os modelos ajustados na profundidade de $0-5 \mathrm{~cm}$

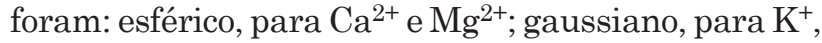
areia, silte e argila; e exponencial, para $\mathrm{pH} \mathrm{e} \mathrm{H}+\mathrm{Al}$. Na profundidade de 5-10 cm, foram: esférico, para argila; gaussiano, para $\mathrm{Ca}^{2+}, \mathrm{Mg}^{2+}, \mathrm{pH}$, areia e silte; e exponencial, para $\mathrm{H}+\mathrm{Al}$. Na profundidade de 10 $15 \mathrm{~cm}$ foram: esférico, para $\mathrm{K}^{+}$; gaussiano, para $\mathrm{Ca}^{2+}$, $\mathrm{Mg}^{2+}$, silte e argila; e exponencial, para $\mathrm{pH}, \mathrm{H}+\mathrm{Al} \mathrm{e}$ areia (Quadro 2).

O alcance é a distância da origem a partir da qual as amostras não são correlacionadas (Goovaerts, 1997). Quando o ajuste é esférico, todos os pontos de um círculo com esse raio são tão similares que podem ser usados para estimar valores para qualquer ponto entre eles (Machado et al., 2007). Os menores e maiores alcances foram de $66,85 \mathrm{~m}$ para argila e de $1.232,70 \mathrm{~m}$ para acidez total, respectivamente (Quadro 2).

Houve tendência de aumento dos teores de $\mathrm{Ca}^{2+}$ (Figura 2) à medida que a posição do relevo passava do topo para o pedimento e da pastagem para o Cerrado nativo, ou seja, os maiores valores foram observados no Cerrado nativo associados a pedimento, e, em profundidade, os teores de $\mathrm{Ca}^{2+}$ aumentaram. Ressaltase que os teores de $\mathrm{Mg}^{2+}$ (Figura 2) seguiram a mesma tendência do $\mathrm{Ca}^{2+}$. Com relação à posição do relevo, os resultados assemelham-se aos encontrados por
Borém \& Ramos (2002), em que os teores de $\mathrm{Ca}^{2+}$ foram maiores no pedimento e meia-encosta, e os menores, no topo.

No tocante ao manejo do solo, o comportamento do


eficiente efetuada pela vegetação natural, o que foi observado por estudos de Araújo et al. (2004) e Silva et al. (2007). Segundo Primavesi (1980), os menores valores encontrados na pastagem podem também ser atribuídos à lixiviação ocorrida em solos dos ecossistemas tropicais.

Os teores de $\mathrm{K}^{+}$(Figura 2) não variaram com a substituição do Cerrado nativo pela pastagem, e sim com a posição do relevo e com a profundidade; os maiores valores foram encontrados no pedimento, na profundidade de $0-5 \mathrm{~cm}$. Os menores teores foram encontrados em profundidade devido provavelmente à maior facilidade de lixiviação do $\mathrm{K}^{+}$em relação ao $\mathrm{Ca}^{2+}$ e $\mathrm{Mg}^{2+}$. Araújo et al. (2004) observaram maiores teores nos primeiros centímetros e até próximo a $10 \mathrm{~cm}$ de profundidade. No entanto, no Cerrado nativo, somente o primeiro centímetro de solo mostrou teor médio de $\mathrm{K}^{+}\left(52 \mathrm{mg} \mathrm{dm}^{-3}\right)$; as demais camadas apresentaram teores baixos. Segundo esses autores, nas áreas cultivadas com pastagem, a distribuição de $\mathrm{K}^{+}$ocorre de acordo com a profundidade, apresentando variações maiores nos primeiros $5 \mathrm{~cm}$.

Quadro 2. Modelos e parâmetros estimados dos semivariogramas para as variáveis $\mathrm{Ca}^{2+}, \mathrm{Mg}^{2+}, \mathrm{K}^{+}, \mathrm{pH}, \mathrm{H}+\mathrm{Al}$, areia, silte e argila nas profundidades avaliadas

\begin{tabular}{|c|c|c|c|c|c|c|}
\hline Atributo & Direção & Modelo & Efeito Pepita $\left(C_{0}\right)$ & Patamar $\left(C_{0}+C_{1}\right)$ & Alcance, m (a) & $\mathbf{R}^{2}$ \\
\hline & \multicolumn{6}{|c|}{$0-5 \mathrm{~cm}$} \\
\hline $\mathrm{Ca}^{2+}\left(\mathrm{mmol}_{\mathrm{c}} \mathrm{dm}^{-3}\right)$ & Esférico & Isotrópico & 0,91 & 7,75 & 93,00 & 0,38 \\
\hline $\mathrm{Mg}^{2+}\left(\mathrm{mmol}_{\mathrm{c}} \mathrm{dm}^{-3}\right)$ & Esférico & Isotrópico & 2,06 & 11,75 & 104,50 & 0,40 \\
\hline $\mathrm{K}^{+}\left(\mathrm{mmol}_{\mathrm{c}} \mathrm{dm}^{-3}\right)$ & Gaussiano & Isotrópico & 30,00 & 570,90 & 239,36 & 0,65 \\
\hline $\mathrm{pH}$ & Exponencial & Isotrópico & 0,016 & 0,064 & 114,56 & 0,50 \\
\hline $\mathrm{H}+\mathrm{Al}\left(\mathrm{mmol}_{\mathrm{c}} \mathrm{dm}^{-3}\right)$ & Exponencial & Isotrópico & 0,85 & 5,65 & 1232,70 & 0,52 \\
\hline Areia $(\%)$ & Gaussiano & Isotrópico & 25,50 & 226,50 & 111,54 & 0,66 \\
\hline Silte (\%) & Gaussiano & Isotrópico & 11,00 & 332,90 & 269,68 & 0,76 \\
\hline \multirow[t]{2}{*}{ Argila (\%) } & Gaussiano & Isotrópico & 11,60 & 52,80 & 66,85 & 0,21 \\
\hline & \multicolumn{6}{|c|}{$5-10 \mathrm{~cm}$} \\
\hline $\mathrm{Ca}^{2+}\left(\mathrm{mmol}_{\mathrm{c}} \mathrm{dm}^{-3}\right)$ & Gaussiano & Isotrópico & 0,39 & 12,87 & 135,61 & 0,70 \\
\hline $\mathrm{Mg}^{2+}\left(\mathrm{mmol}_{\mathrm{c}} \mathrm{dm}^{-3}\right)$ & Gaussiano & Isotrópico & 0,59 & 29,77 & 218,75 & 0,65 \\
\hline $\mathrm{K}^{+}\left(\mathrm{mmol}_{\mathrm{c}} \mathrm{dm}^{-3}\right)$ & Gaussiano & Isotrópico & 47,00 & 404,90 & 298,77 & 0,51 \\
\hline $\mathrm{pH}$ & Gaussiano & Isotrópico & 0,05 & 0,1174 & 123,84 & 0,94 \\
\hline $\mathrm{H}+\mathrm{Al}\left(\mathrm{mmol}_{\mathrm{c}} \mathrm{dm}^{-3}\right)$ & Exponencial & Isotrópico & 1,62 & 7,249 & 1232,70 & 0,19 \\
\hline Areia $(\%)$ & Gaussiano & Isotrópico & 5,00 & 500,10 & 185,32 & 0,83 \\
\hline Silte (\%) & Gaussiano & Isotrópico & 8,70 & 218,30 & 214,42 & 0,94 \\
\hline \multirow[t]{2}{*}{ Argila (\%) } & Esférico & Isotrópico & 1,20 & 65,90 & 117,10 & 0,36 \\
\hline & \multicolumn{6}{|c|}{$0-15 \mathrm{~cm}$} \\
\hline $\mathrm{Ca}^{2+}\left(\mathrm{mmol}_{\mathrm{c}} \mathrm{dm}^{-3}\right)$ & Gaussiano & Isotrópico & 1,36 & 14,95 & 171,12 & 0,80 \\
\hline $\mathrm{Mg}^{2+}\left(\mathrm{mmol}_{\mathrm{c}} \mathrm{dm}^{-3}\right)$ & Gaussiano & Isotrópico & 1,07 & 19,29 & 172,16 & 0,82 \\
\hline $\mathrm{K}^{+}\left(\mathrm{mmol}_{\mathrm{c}} \mathrm{dm}^{-3}\right)$ & Esférico & Isotrópico & 16,8 & 139,70 & 131,50 & 0,31 \\
\hline $\mathrm{pH}$ & Exponencial & Isotrópico & 0,06 & 0,13 & 468,90 & 0,54 \\
\hline $\mathrm{H}+\mathrm{Al}\left(\mathrm{mmol}_{\mathrm{c}} \mathrm{dm}^{-3}\right)$ & Exponencial & Isotrópico & 1,26 & 3,77 & 1232,7 & 0,41 \\
\hline Areia $(\%)$ & Exponencial & Isotrópico & 1,00 & 412,90 & 472,2 & 0,54 \\
\hline Silte (\%) & Gaussiano & Isotrópico & 3,00 & 148,60 & 179,26 & 0,74 \\
\hline Argila (\%) & Gaussiano & Isotrópico & 5,40 & 51,86 & 106,69 & 0,36 \\
\hline
\end{tabular}


$\mathrm{O} \mathrm{pH}$ (Figura 2) variou pouco, cerca de 0,6 unidade, indicando que a variação dos teores dos nutrientes no solo deveu-se ao desmatamento e à posição do relevo e não à mudança de $\mathrm{pH}$. Nas profundidades de $5-10 \mathrm{e}$ $10-15 \mathrm{~cm}$, foi verificada leve tendência de redução no pH no topo e pedimento. Em relação à acidez total (Figura 2), observaram-se maiores teores na área de pastagem associada ao topo, em todas as profundidades avaliadas, o que indica que, quando a vegetação original é retirada para implantação de pastagem, há aumento da acidez total do solo. Segundo Pavan (1997), o acúmulo de matéria orgânica no solo significa redução de perdas de ânions orgânicos do sistema e aumento do consumo de $\mathrm{H}^{+}$.

Houve decréscimo dos teores de areia do topo para a meia-encosta e aumento da meia-encosta para o pedimento em todas as profundidades avaliadas (Figura 2), indicando que o processo de erosão laminar pode estar acontecendo de forma mais acentuada na camada superficial, já que a cobertura vegetal do pasto é reduzida quando comparada à do Cerrado nativo.

Independentemente da posição do relevo, do manejo do solo e da profundidade, em geral, silte e argila (Figura 2) apresentaram valores inversamente proporcionais aos valores de areia. Os teores de argila foram maiores quando se passou da meia-encosta para o pedimento nas três profundidades estudadas; na profundidade de 10-15 cm, os valores também foram maiores no pedimento.

\section{CONCLUSÕES}

1. O desmatamento para implantação de pastagem extensiva em topossequência não alterou os teores de C orgânico na profundidade de $0-15 \mathrm{~cm}$, reduziu os teores de $\mathrm{P}, \mathrm{Ca}^{2+} \mathrm{e} \mathrm{Mg}^{2+}$ e aumentou a acidez total do solo.

2. O cultivo em topossequência alterou as frações granulométricas, devido à erosão laminar.

\section{AGRADECIMENTOS}

Ao Conselho Nacional de Desenvolvimento Científico e Tecnológico ( $\mathrm{CNPq})$, pelas bolsas concedidas. Ao pós-graduando da FCAV/UNESP Carlos Alberto Kenji Taniguchi.

\section{LITERATURA CITADA}

ADDISCOTT, T.M. \& THOMAS, D. Tillage, mineralization and leaching: Phosphate. Soil Till. Res., 53:255-273, 2000.

ALVES, A.J.O. \& RIBEIRO, M.R. Caracterização e gênese dos solos de uma topossequência na microrregião da Mata de Pernambuco. R. Bras. Ci. Solo, 19:297-305, 1995.
ARAÚJO, E.A.; LANI, J.L.; AMARAL, E.F. \& GUERRA, A. Uso da terra e propriedades físicas e químicas de Argissolo Amarelo distrófico na Amazônia Ocidental. R. Bras. Ci. Solo, 28:307-315, 2004.

BONILLA, A.L.C. Balanço de nitrogênio em microbacias pareadas (floresta vs pastagem) no Estado de Rondônia. Piracicaba, Escola Superior de Agricultura Luiz de Queiroz, 2005. 69p. (Tese de Mestrado)

BORÉM, R.A.T. \& RAMOS, D.P. Variação estacional e topográfica de nutrientes na serapilheira de um fragmento de mata atlântica. Cerne, 8:42-59, 2002.

CAMARGO, O.A.; MONIZ, A.C.; JORGE, J.A. \& VALADARES, J.M.A.S. Métodos de análise química, mineralógica e física de solos do Instituto Agronômico de Campinas. Campinas, Instituto Agronômico de Campinas, 1986. 94p.

CERRI, C.C.; FELLER, C. \& CHAUVEL, A. Evolução das principais características de um Latossolo VermelhoEscuro após desmatamento e cultivo por doze e cinqüenta anos com cana-de-açúcar. Cah. Orst., 26:37-50, 1991.

CERRI, C.C.; MORAES, J.F.L. \& VOLKOFF, B. Dinâmica do carbono orgânico em solos vinculados a pastagens da Amazônia brasileira. Invest. Agr., 1:95-102, 1992.

CHONÉ, T.; ANDREUX, F.; CORREA, J.C.; VOLKOFF, B. \& CERRI, C.C. Changes in organic matter in an Oxisol from the central Amazon Forest during eight years as pasture, determined by ${ }^{13} \mathrm{C}$ isotopic composition. In: BERTHELIN, J., ed. Diversity of environmental biogeochemistry. Amsterdam, Elsevier, 1991. p.397-405.

DAY, P.R. Particle fracionation and particle size analysis. In: BLAKE, C.A., ed. Method of soil analysis. Madison, American Society of Agronomy, 1965. p.545-567.

DECHEN, S.C.F.; DE MARIA, I.C.; CASTRO, O.M. \& VIEIRA, S.R. Manejo de solos tropicais no Brasil. In: REUNIAO BRASILEIRA DE MANEJO E CONSERVAÇÃO DO SOLO, 15., Santa Maria, 2004. Anais. Santa Maria, Sociedade Brasileira de Ciência do Solo, 2004. p.1-28.

DEMATTÊ, J.L.I.; MAZZA, J.A. \& DEMATTÊ, J.A.M. Caracterização e gênese de uma topossequência Latossolo Amarelo-Podzol originado de material da formação Barreiras - Estado de Alagoas. Sci. Agric., 53:20-30, 1996.

DIEZ, J.A. POLO, A.; DIAZ-BURGOS, M.A.; CERRI, C.C.; FIEGL, B.J. \& PICOLLO, M.C. Effect of fallow land cultivated pasture and abandoned pasture on soil fertility in two deforest Amozonian regions. Sci. Agric., 24:45-52, 1997.

EMPRESA BRASILEIRA DE PESQUISA AGROPECUÁRIA . EMBRAPA. Sistema brasileiro de classificação de solos. Rio de Janeiro, 1999. 412p.

EMPRESA BRASILEIRA DE PESQUISA AGROPECUÁRIA EMBRAPA. Manual de métodos de análises do solo. 2.ed. Rio de Janeiro, 1997. 212p.

FALLEIRO, R.M.; SOUSA, C.M.; SILVA, C.S.W.; SEDIYAMA, C.S.; SILVA, A.A. \& FAGUNDES, J.L. Influência dos sistemas de preparo nas propriedades químicas e físicas do solo. R. Bras. Ci. Solo, 27:1097-1104, 2003.

FERNANDES, F.A.; CERRI, C.C. \& FERNANDES, A.H.B.M. Alterações na matéria orgânica e nas características químicas de um Podzol Hidromórficos sob pastagens cultivadas no Pantanal Sul-Mato-Grossense. Corumbá, Embrapa Pantanal, 2002. 28p. 
FONSECA, S. Propriedades físicas, químicas e microbiológicas de um Latossolo Vermelho-Amarelo sob eucalipto, mata natural e pastagens. Viçosa, MG, Universidade Federal de Viçosa, 1984. 78p. (Tese de Mestrado)

FRAGA, V.S. \& SALCEDO, I.H. Declines of organic nutrient pools in tropical semi arid soils under subsistence farming. Soil Sci. Soc. Am. J., 68:215-224, 2004.

GOOVAERTS, P. Geostatistics for natural resources evaluation. New York, Oxford University Press, 1997. $512 \mathrm{p}$.

GREELAND. D.J. \& NEY, P.H. Increases in the carbon and nitrogen contents of tropical soil under natural fallow. J. Soil. Sci., 10:284-299, 1959.

LAL, R. Soil carbon dynamics in cropland and rangeland. Environ. Pollution, 116:353-362, 2002.

LONGO R.M. \& ESPÍNDOLA C.R. C-orgânico, N-total e substâncias húmicas sob influência da introdução de pastagens (Brachiaria sp.) em áreas de Cerrado e floresta amazônica. R. Bras. Ci. Solo, 24:723-729, 2000.

MACHADO, L.D.; LANA, A.M.Q.; LANA, R.M.Q.; GUIMARÃES, E.C. \& FERREIRA, C.V. Variabilidade espacial de atributos químicos do solo em áreas sob sistema plantio convencional. R. Bras. Ci. Solo, 31:591-599, 2007.

MARTINS, P.S.F.; CERRI, C.C.; VOLKOFF, B.; ANDREUX, F. \& CHAUVEL, A. Consequences of clearing and tillage on the soil of a natural Amazonian ecosystem. For. Ecol. Manag., 28:273-282, 1991.

MARTINS, P.F.S.; CERRI, C.C.; VOLKOFF, B. \& ANDREUX, F. Conseqüências do cultivo e do pousio sobre a matéria orgânica do solo sob floresta natural na Amazônia Oriental. Acta Amaz., 2:19-28, 1990.

MORAES, A. Pastagem como fator de recuperação de áreas degradadas. In: SIMPÓSIO SOBRE ECOSSISTEMA DE PASTAGEM, 2., Jaboticabal, 1993. Anais. Jaboticabal, 1993. p.191-221.

MORAES, J.F.L. Conteúdos de carbono e tipologia de horizontes nos solos da bacia Amazônica. Piracicaba, Centro de Energia Nuclear na Agricultura, 1991. 84p. (Tese de Mestrado)

MORAES, J.F.L.; VOLKOFF, B.; CERRI, C.C. \& BERNOUX, M. Soil properties under Amazon forest and changes due pasture installation in Rondônia, Brazil. Geoderma, 70:6381, 1996.
MORETI, D.; ALVES, M.C.; VALÉRIO FILHO, W.V. \& CARVALHO, M.P. Atributos químicos de um Latossolo Vermelho sob diferentes sistemas de preparo, adubações e plantas de cobertura. R. Bras. Ci. Solo, 31:167-175, 2007.

OLIVEIRA, R.R. Produção e decomposição de serapilheira no Parque Nacional da Tijuca, RJ. Rio de Janeiro, Instituto de Geociências,1987. 107p. (Tese de Mestrado)

PAVAN, M.A.; CHAVES, J.C.D.; SIQUEIRA, R. \& ANDROCIOLI FILHO, A. O sistema de plantio adensado e a melhoria da fertilidade do solo. Piracicaba, Potafós, 1997. p.1-7.

PRIMAVESI, A. O manejo ecológico do solo: Agricultura em regiões tropicais. São Paulo, Nobel, 1980. 541p.

ROBERTSON, G.P. $G S^{+}$geostatistics for the environmental sciences: $\mathrm{GS}^{+}$user' guide. Plainwell, Gamma Design Software, 1998. 152p.

ROSCOE, R.; BUURMAN, P.; VELTHORST, E.J. \& VASCONCELLOS, C.A. Soil organic matter dynamics in density and particle size fractions as revealed by the ${ }^{13} \mathrm{C} /$ ${ }^{12} \mathrm{C}$ isotopic ratio in a Cerrado's Oxisol. Geoderma, 104:185-202, 2001.

SALTON, J.C. Matéria orgânica e agregação do solo na rotação lavoura-pastagem em ambiente tropical. Porto Alegre, Universidade Federal do Rio Grande do Sul, 2005. (Tese de Doutorado)

SALTON, J.C. \& HERNANI, L.C. Adoção. In: SALTON, J.C.; HERNANI, L.C. \& FONTE, C.Z. Sistema de plantio direto. Brasília, Embrapa Agropecuária Oeste, 1998. p.21-35.

SANCHEZ, P.A.; VILLACHICA, J.H. \& BANDY, D.E. Soil fertility dynamics after clearing a tropical rainforest in Peru. Soil. Sci. Soc. Am. J., 47:1171-1178, 1983.

SANTOS, A.C. Fertilidade do solo e redistribuição de ${ }^{137} \mathrm{Cs}$ em função da cobertura vegetal, relevo, e classes texturais, em uma microbacia hidrográfica do Estado da Paraíba. Recife, Universidade Federal de Pernambuco, 2004. 67p. (Tese de Doutorado)

SILVA, C.R.; PEREIRA, J.M.; ARAÚJO, Q.R.; PIRES, A.J.V. \& DEL REI, A.J. Alterações nas propriedades químicas e físicas de um Chernossolo com diferentes coberturas vegetais. R. Bras. Ci. Solo, 31:101-107, 2007.

VELDKAMP, E. Organic carbon turnover in tropical soils under pastures after deforestation. Soil Sci. Soc. Am. J., 58:175-180, 1994. 